\begin{tabular}{|c|c|c|}
\hline $\begin{array}{l}\text { 2. To: (Receiving organization) } \\
\text { Distribution }\end{array}$ & $\begin{array}{l}\text { 3. From: (originating organization) } \\
\text { LDUA Project }\end{array}$ & $\begin{array}{r}\text { 4. Related EDT No.: } \\
\text { N/A }\end{array}$ \\
\hline $\begin{array}{l}\text { 5. Proj./Prog./Dept./Div.: } \\
\text { TWRS }\end{array}$ & $\begin{array}{l}\text { 6. Design Authority/ Design Agent/Cog. } \\
\text { Engr.: } \\
\text { GA Barnes }\end{array}$ & $\begin{array}{l}\text { 7. Purchase order No.: } \\
\qquad N / A\end{array}$ \\
\hline \multirow{2}{*}{\multicolumn{2}{|c|}{$\begin{array}{l}\text { 8. Originator Remarks: } \\
\text { ETN-96-0007 }\end{array}$}} & $\begin{array}{r}\text { 9. Equip./Component No.: } \\
\text { LDUA/6230 }\end{array}$ \\
\hline & & $\begin{array}{l}\text { 10. System/Bldg./Facility: } \\
\text { N/A }\end{array}$ \\
\hline \multirow{3}{*}{\multicolumn{2}{|c|}{ 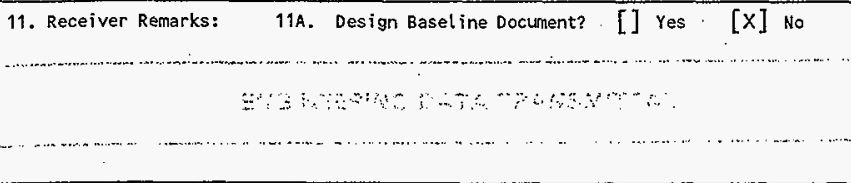 }} & $\begin{array}{l}\text { 12. Major Assm. DWg. No.: } \\
\text { N/A }\end{array}$ \\
\hline & & $\begin{array}{l}\text { 13. Permit/Permit Application No.: } \\
\mathrm{N} / \mathrm{A}\end{array}$ \\
\hline & & $\begin{array}{l}\text { 14: Required Response Date: } \\
\text { February 28, } 1997\end{array}$ \\
\hline
\end{tabular}

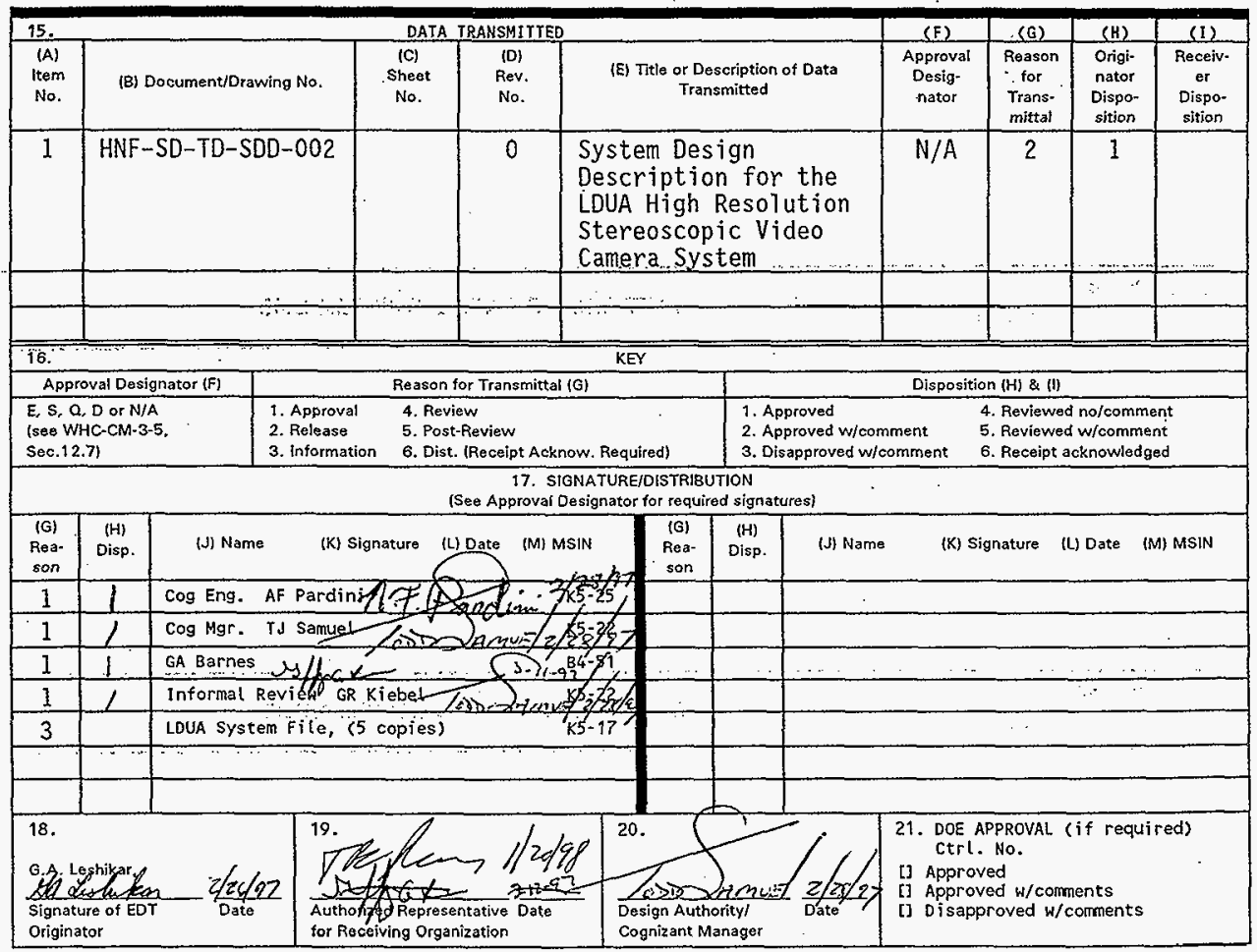




\title{
System Design Description for the LDUA High Resolution Stereoscopic Video Camera System
}

\author{
AF Pardini \\ Pacific Northwest National Laboratory, Richland, WA 99352 \\ U:S. Department of Energy Contract DE-AC06-87RL10930 \\ EDT/ECN: EDT 620933 \\ Org Code: $08 E 00$ \\ UC: 2030 \\ B\&R Code: EW 3130010 \\ Charge Code: E20133 \\ Total Pages: 10 \\ Key Words: LDUA, Light Duty Utility Arm, HRSVS, robot arm, \\ stereoscopic, end effector \\ Abstract: This document describes the workings of the LDUA High \\ Resolution Stereoscopic Video Camera System (HRSVS), system 6230. The \\ HRSVS is a dual color camera system designed to provide stereo viewing \\ of the interior of waste tanks in a Class 1, Division 1, flammable \\ atmosphere. The HRSVS is an end effector to the LDUA.
}

TRADEMARK DISCLAIMER. Reference herein to any specific commercial product, process, or service by trade name, trademark, manufacturer, or otherwise, does not necessarily constitute or imply its endorsement, recommendation, or favoring by the United States Government or any agency thereof or its contractors or subcontractors.

Printed in the United States of America. To obtain copies of this document, contact: WHC/BCS Document Control Services, P.O. Box 1970, Mailstop H6-08, Richland WA 99352, Phone (509) 372-2420; Fax (509) 376-4989.
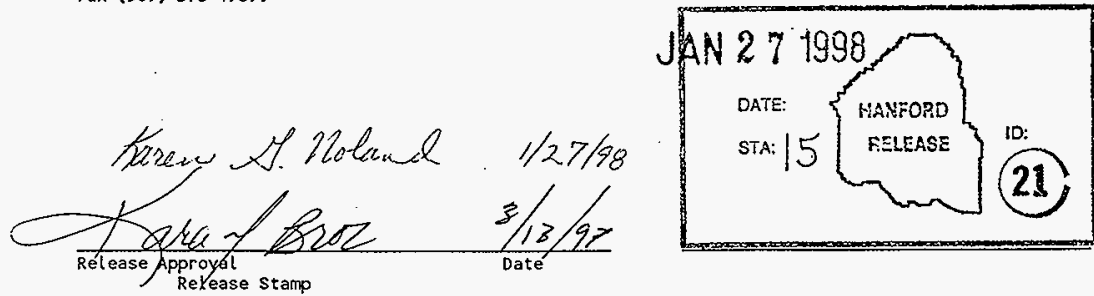
HNF-SD-TD-SDD-002, Rev. 0

SYSTEM DESIGN DESCRIPTION FOR THE LIGHT DUTY

UTILITY ARM HIGH RESOLUTION STEREOSCOPIC VIDEO CAMERA SYSTEM (HRSVS)

Revision 1

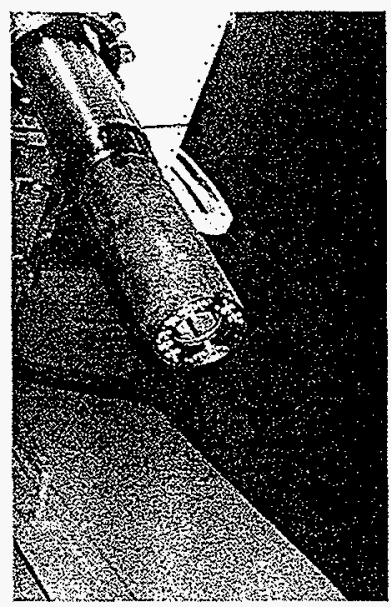

November 13, 1996

BY

A. F. PARDINI

SENSORS AND MEASUREMENT SYSTEMS

PACIFIC NORTHWEST NATIONAL LABORATORY

RICHLAND, WASHINGTON 


\title{
TABLE OF CONTENTS
}

\author{
SYSTEM DESIGN DESCRIPTION FOR THE LIGHT DUTY \\ UTILITY ARM HIGH RESOLUTION STEREOSCOPIC VIDEO CAMERA SYSTEM \\ (HRSVS)
}

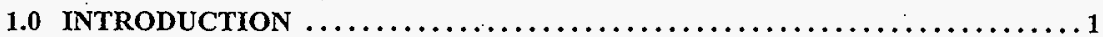

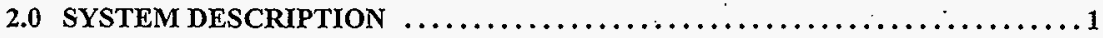

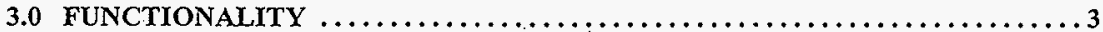

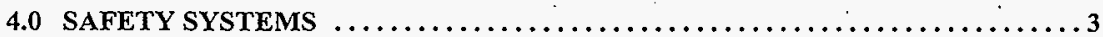

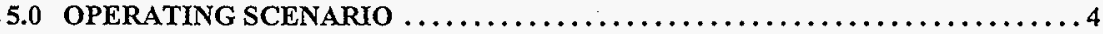

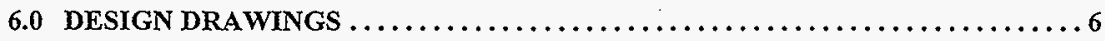




\section{SYSTEM DESIGN DESCRIPTION FOR THE LIGHT DUTY UTILTTY ARM HIGH RESOLUTION STEREOSCOPIC VIDEO CAMERA SYSTEM (HRSVS)}

\subsection{INTRODUCTION}

The High Resolution Stereoscopic Video Camera System (FIRSVS), system 6230, was designed to be used as an end effector on the LDUA to perform surveillance and inspection activities within a waste tank. It is attached to the LDUA by means of a Tool Interface Plate (TIP) which provides a feed through for all electrical and pneumatic utilities needed by the end effector to operate.

Designed to perform up close weld and corrosion inspection roles in UST operations, the HRSVS will support and supplement the Light Duty Utility Arm (LDUA) and provide the crucial inspection tasks needed to ascertain waste tank condition.

\subsection{SYSTEM DESCRIPTION}

The HRSVS is shown as an end effector on the LDUA (Figure 1) and will interface to the LDUA Supervisory Data Acquisition System (SDAS) through a fiber optic cable.

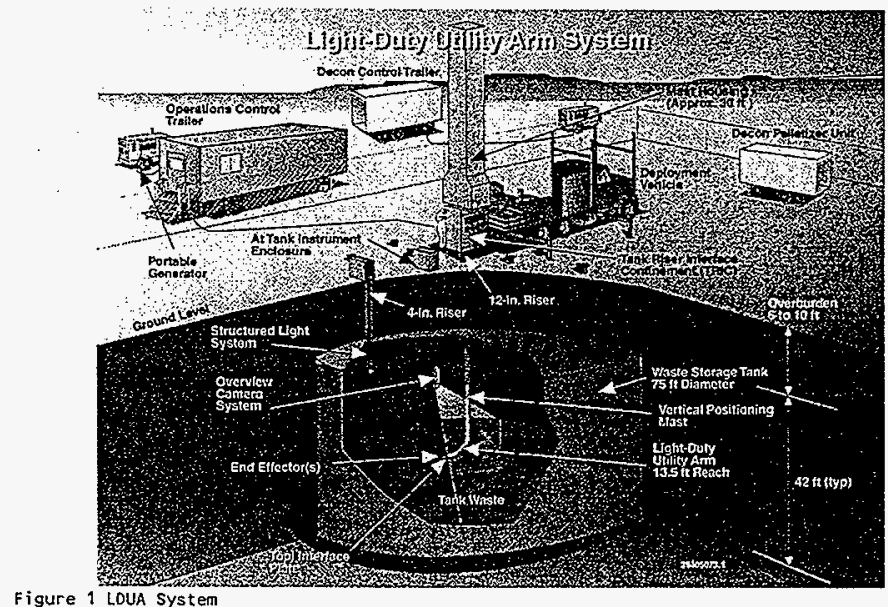


The system consists of the HRSVS end effector and associated support electronics located in the At Tank Instrument Enclosure (ATIE). These support electronics are the Common Video End Effector (CVEE) systems that provide the interface control of the end effector by the LDUA SDAS. The end effector includes 1 black and white camera and 1 color camera located near the front of the end effector. The purpose of these cameras is to provide general tank feature observations from a distance and to assist the LDUA in maneuvering close to in-tank structures for closer viewing using the stereoscopic cameras.

Located within the end effector nearer the TIP are two color cameras with fixed lenses. This combination of color cameras and lenses provide closeup 3-D viewing of tank features such as corrosion and tank wall pitting. Figure 2 shows the internals of the HRSVS end effector with its various camera systems.

All camera functions are controlled using the LDUA Supervisory Data Acquisition System (SDAS).

In the event of a low purge pressure, a signal from the LDUA control system will be provided to the end effector support electronics to instigate a shutdown of all power to the end effector. All functions will be controlled remotely from the Operations Control Trailer.

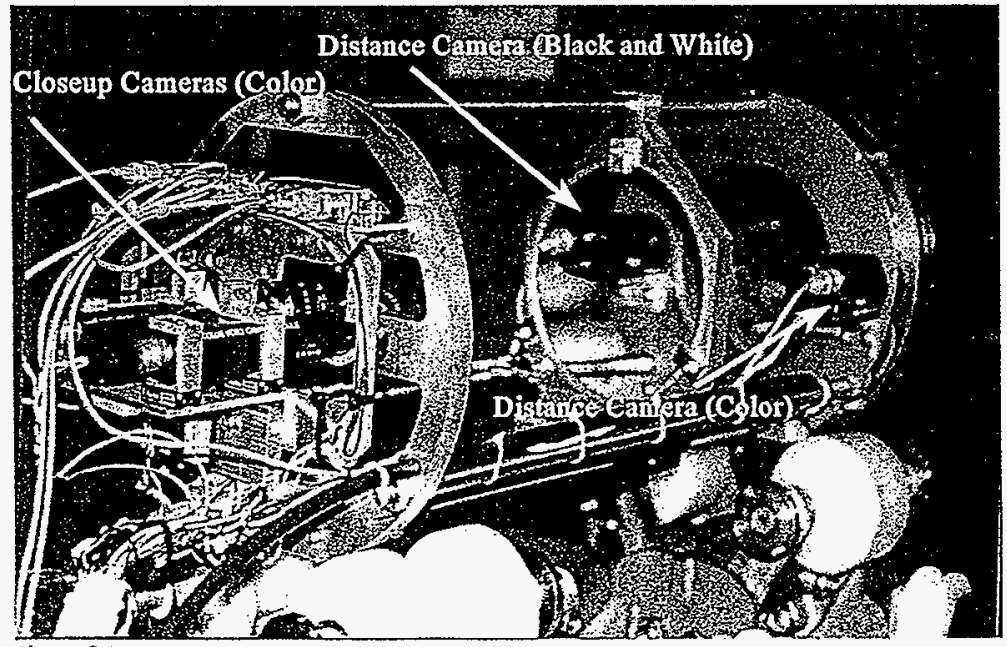

Figure 2 HRSVS Camera systems 


\subsection{FUNCTIONALITY}

The basic functions of the HRSVS include:

Vertical/Horizontal motion - The LDUA will provide all movement of the end effector.

Lighting - The camera is configured with 10 lights, each rated at 35 watts. Thus the total light wattage is 350 watts. Each pair of lights can be separately operated, either off of on.

Camera - The cameras used in the HRSVS for distance viewing are a black and white camera with a low lux rating of 0.03 and a color camera with a lux rating of 2 . The cameras are not radiation hardened but will withstand enough radiation (roughly $1 \times 10^{4}$ ) to survive to perform the surveillance task. The cameras used in the HRSVS for closeup viewing are color cameras with lux rating of 4.5. The cameras are not radiation hardened but will withstand enough radiation (roughly $1 \times 10^{4}$ ) to survive to perform the inspection task.

Lens - The lenses used on the distance cameras are fixed $6 \mathrm{~mm}$ lenses. The lenses are not radiation hardened but will withstand enough radiation (roughly $1 \times 10^{4}$ ) to survive to perform the surveillance task. The lenses used on each of the closeup cameras are fixed $\mathbf{5 0}$ $\mathrm{mm}$ lenses. The lenses are not radiation hardened but will withstand enough radiation (roughly $1 \times 10^{4}$ ) to survive to perform the inspection task. The HRSVS also includes a large $1000 \mathrm{~mm}$ focusing lens. This lens can move over the entire distance between the fixed color camera lenses and the end plate of the end effector providing precision image focusing.

\subsection{SAFETY SYSTEMS}

The HRSVS was designed to assist the LDUA in meeting the requirements of NFPA 70 National Electric Code (1993), for use in class 1, division 1, group B, flammable atmospheres. This requirement is met as the HRSVS is the same volume as the LDUA and the purge gas entrance point in to the purged volume is at the end of the HRSVS, thus allowing the purge gas to sweep the HRSVS volume and then the rest of the LDUA system. Pressure sensors located on the LDUA system provide a signal to the HRSVS electronics indicating a need to shutdown due to loss of purge pressure. The HRSVS electronics will then shutdown all power to the end effector. 


\subsection{OPERATING SCENARIO}

This section provides instructions for the normal handling and operation of the HRSVS in support of routine operations of the LDUA within a Hanford tank.

\section{Equipment Setup}

The HRSVS will be stored in a plastic bag within the hard plastic storage container. The top section of the storage container will be removed exposing the top of the end effector. Once the plastic bag is removed the end effector will be available for removal from the storage container using the Manual End Effector Exchange System (MEEES).

The door of the TRIC will be opened and the MEEES will place the HRSVS in position for connection to the LDUA. This is accomplished using the TIP connecting mechanism.

Under normal operation the CVEE chassis and CVEE power supply chassis will be energized and all cable connections between the CVEE chassis and the LDUA interface will be made. Therefore once the HRSVS end effector is placed on the arm the system will be ready for operation. Actual operation of the HRSVS is performed utilizing SDAS. The SDAS Virtual Instrument (VI) (Figure 3) will be used to remotely operate the HRSVS.

Using the VI the operator can turn on pairs of lights for improved viewing. The operator can easily switch between the closeup stereo cameras

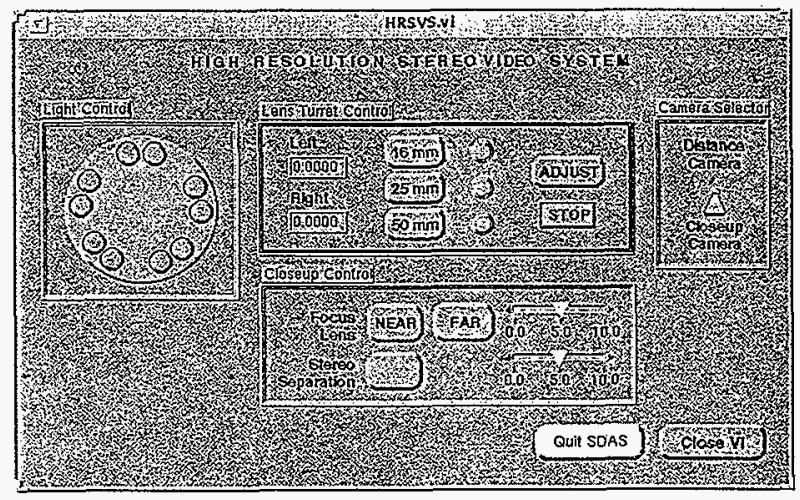

Figure 3 HRSVS Virtual Instrument (VI) and the distance cameras. 


$$
\text { HNF-SD-TD-SDD-002, ReV. } 0
$$

\section{Theory of Operation}

Once the HRSVS is placed on the LDUA it will be lowered into the waste tank. The black and white and color distance cameras will be used first to provide an overview of the internal features of the waste tank. Both cameras are outfitted with $6 \mathrm{~mm}$ lenses. The black and white camera is a low lux camera and should not require an excessive amount of light for proper operation. The LDUA will provide general movement of the end effector within the waste tank. The black and white camera or the color camera can be used to pick out interesting in-tank features that the operator can then look at using the closeup stereo system.

Once a feature has been picked out, the black and white camera or color camera will provide enough visual information for the LDUA operator to maneuver the LDUA within approximately 3 feet of the feature to be observed. The operator can then switch to the color stereo camera pair and look at the feature using the stereoscopic system. The LDUA will be used for gross focusing by moving the HRSVS closer to or away from the feature. Once the feature is relatively in focus, the HRSVS large focusing lens ean be adjusted for optimum viewing (Figure 4). Some precise vertical and horizontal image adjustments can be made by the stereo system located in the Operations Control Trailer (OCT) along with some color and contrast enhancement.

After the HRSVS has performed it task of surveillance and inspection, it will be raised out of the tank and removed from the LDUA, and other end effectors can now be used.

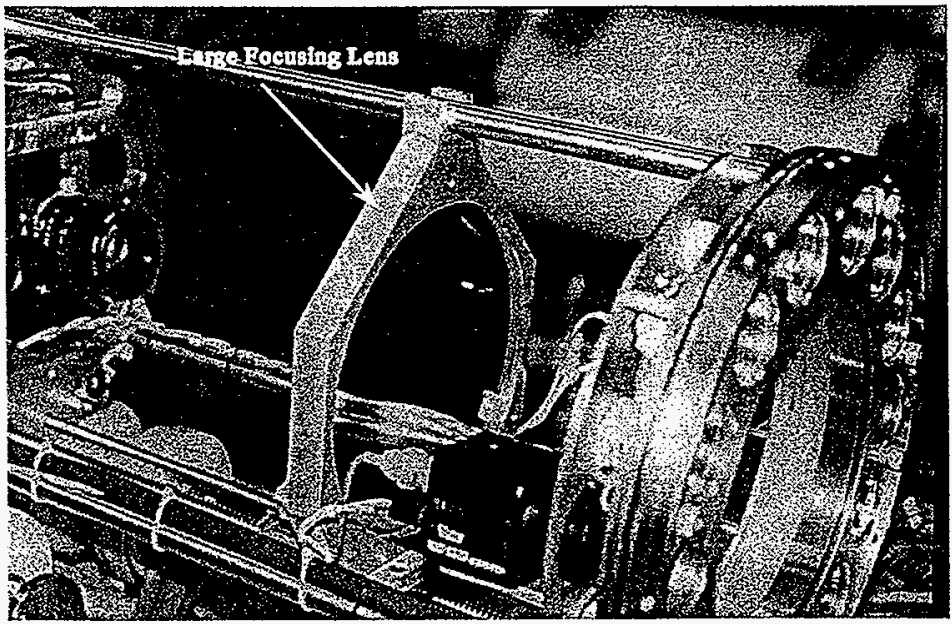

Figure 4 Large focusing Lens 


$$
\text { HNF-SD-TD-SDD-002, Rev. } 0
$$

\subsection{DESIGN DRAWINGS}

The following is a complete list of drawings which constitute the mechanical and electrical drawings for the HRSVS (sometimes referred to as the close-up stereo video system (CSVS). Also shown are the CVEE support electronics drawings. Listed below the WHC drawing number is the Savannah River Technology Center reference drawing number.

\section{MECHANICAL DRAWINGS}

H-6-14242 SH 1 Rev. 0

(EES-22408-R1-027 Rev. B)

H-6-14242 SH 2 Rev. 0

(EES-22408-R1-027 Rev. B)

H-6-14243 SH 1 Rev. 0

(EES-22408-R4-028 Rev. B)

H-6-14243 SH 2 Rev. 0

(EES-22408-R4-029 Rev. B)

H-6-14243 SH 3 Rev. 0

(EES-22408-R4-031 Rev. B)

H-6-14244 Rev. 0

(EES-22408-R4-030 Rev. B)

H-6-14245 Rev. 0

(EES-22408-R3-032 Rev. B)

\section{ELECTRICAL DRAWINGS}

H-6-14246 Rev. 0

(EES-22408-L7-048 Rev. B)
Close-Up Video System Assembly

Close-Up Video System Assembly

Close-Up Video System Details - Sheet 1

Close-Up Video System Details - Sheet 2

Close-Up Video System Details - Sheet 3

Close-Up Video System Camera Housing Weldment

Close-Up Video System Light Baffe

Weldment and Misc Details

UST-ID Close-Up Stereo Camera Housing Schematic 
CVEE DRAWINGS

CVEE CHASSIS

H-6-14270 Rev. A Sheet 1 of 8 Common Video End Effector (CVEE) Support Electronics

H-6-14270 Rev. A Sheet 3 of 8 CVEE and HRSVS end to end drawing

H-6-14270 Rev. A Sheet 4 of 8 Common Video End Effector (CVEE) Chassis Layout

H-6-14270 Rev. A Sheet 5 of 8 CVEE Chassis Preparation

H-6-14270 Rev. A Sheet 6 of 8 CVEE Chassis Wiring Diagram (Part A)

H-6-14270 Rev. A Sheet 7 of 8 CVEE Wiring Diagram (Part B)

H-6-14270 Rev. A Sheet 8 of 8 CVEE/PC Serial Connections

POWER SUPPLY DRAWINGS

H-6-14271 Rev. A Sheet 1 of 3 WHC Power Chassis Layout (CVEE)

H-6-14271 Rev. A Sheet 2 of 3 WHC Power Chassis Wiring Diagram (CVEE)

H-6-14271 Rev. A Sheet 3 of 3 WHC Power Chassis Schematic (CVEE) 